\title{
PENGARUH MODEL KOOPERATIF TIPE EXAMPLE NON EXAMPLE TERHADAP KEMAMPUAN MENULIS PUISI OLEH SISWA KELAS VIII MTS BINAUL IMAN KARANG SARI
}

\author{
Netti Marini $^{1}$, Fheti Wulandari Lubis ${ }^{2}$ \\ Universitas Simalungun ${ }^{1}$ \\ STKIP Budidaya Binjai
}

\begin{abstract}
ABSTRAK
Penelitian ini bertujuan untuk menjelaskan bagaimana pengaruh model pembelajaran kooperatif tipe example non example terhadap kemampuan menulis puisi siswa. Adapun teknik pengumpulan data pada penelitian ini berbentuk essay test dan teknik pengolahan data yang digunakan dalam penelitian ini adalah analisis korelasi pearson product moment.

Hasil penelitian menunjukkan bahwa ada peningkatan nilai pada kemampuan menulis puisi saat dilaksanakannya pre-test dan post-tes. Nilai rata-rata yang diperoleh saat dilaksanakan pre-test kemampuan siswa dalam menulis puisi adalah 65,48 dan nilai rata-rata yang diperoleh saat dilaksanakan post-test kemampuan siswa dalam menulis puisi adalah 87,91. Diketahui dk $=\mathrm{n}-2$ $=60-2=58$. Untuk penelitian taraf nyata yang dipakai adalah $\alpha=0,5$. Nilai determinasi adalah $36 \%$ dari perhitungan analisis korelasi diperoleh nilai koofisien korelasi $(r)=0,60$ yang digolongkan pada tingkat korelasi sedang. Hasil korelasi tersebut dilanjutkan dengan uji " $\mathrm{t}$ " dan diperoleh hasil $\mathrm{t}$ hitung sebesar 5,70 sedangkan hasil $t$ tabel sebesar 2,021, maka hipotesis alternatif (Ha) diterima dan hipotesis nol (Ho) ditolak. Berdasarkan penelitian yang telah dilakukan dapat disimpulkan bahwa ada pengaruh model kooperatif tipe example non example terhadap kemampuan menulis puisi siswa kelas VIII MTs Binaul Iman Karang Sari.
\end{abstract}

Kata kunci : Menulis Puisi - metode kooperatif - tipe example non example

\section{PENDAHULUAN}

Model pembelajaran kooperatif tipe example non example merupakan tipe pembelajaran yang membelajarkan siswa terhadap permasalahan yang ada disekitar melalui analisis contoh-contoh berupa gambargambar, foto, kasus yang bermuatan masalah yang biasanya dekat dengan permasalahan siswa itu sendiri. Tipe pembelajaran ini digunakan untuk membuat daya tarik siswa terhadap materi yang disajikan yaitu mengenai menulis puisi dengan maksud agar mempermudah mencapai tujuan pembelajaran yang di harapkan terutama dalam kemampuan siswa untuk menulis puisi. Menulis puisi tidaklah semudah membalik telapak tangan. Sebelum kita menulis puisi kita harus memahami hakikat puisi tersebut serta unsurunsur yang terkandung dalam pusi itu, baik unsur fisik maupun unsur batinnya. Dengan pemilihan model pembelajaran yang tepat dapat membantu guru untuk mudah mengajarkan materinya yaitu menulis puisi dan menjadi pembelajaran yang aktif dan menyenangkan. Model pembelajaran kooperatif tipe example non example sangat tepat digunakan untuk menerapkan pembelajaran mengenai menulis puisi karena 
dengan memberikan contoh berupa gambar, foto atau kasus yang bermuatan masalah yang biasa mereka hadapi di kehidupan sehariharinya akan lebih mudah merangsang siswa untuk memunculkan ide dan berfikir serta membangkitkan imajinasinya yang akan di tuangkan dalam bentuk tulisan indah yang padat makna atau sering disebut dengan puisi. Waluyo (2015:1) menyatakan "puisi adalah karya sastra dengan bahasa yang dipadatkan, dipersingkat dan diberi irama dengan bunyi yang padu dan pemilihan kata-kata kias (imajinatif)".

Dengan menggunakan mmodel pembelajaran tipe example non example terhadap kemampuan menulis puisi dapat membantu siswa memiliki pemahaman dari sebuah defenisi, mengantarkan siswa agar terlibat dalam sebuah penemuan dan mendorong siswa untuk membangun konsep secara progresif melalui pengalaman dari gambar-gambar yang ada, siwa juga bisa lebih kritis dalam menganalisis gambar serta dapat menyatakan fikiran dan imajinasinya dengan bebas melalui gambar yang disajikan.

Berdasarkan pemaparan di atas, penulis tertarik untuk melakukan penelitian mengenai "Kemampuan Menulis Puisi dengan Menggunakan Metode Kooperatif Tipe Example non Example" . Rumusan penelitian ini adalah sebagai berikut:

1. Bagaimana pengaruh model kooperatif tipe example non example terhadap kemampuan menulis puisi oleh siswa kelas VIII MTs Binaul Iman Karang Sari?

\section{METODE}

Metode yang digunakan dalam penelitian ini adalah koefisien korelasi product moment. Arikunto (2013:316) menyatakan bahwa "Penelitian korelasi bertujuan untuk menemukan ada tidaknya hubungan dan apabila ada, berta eratnya hubungan serta berarti atau tidak hubungan itu".

\section{HASIL DAN PEMBAHASAN}

Nilai Pre-Test Kemampu Menilis Puisi Siswa Kelas VIII MTs Binaul Iman Karang Sari $(\mathbf{x})$

\begin{tabular}{|c|c|c|c|}
\hline No & Inisial & Skor Ideal & Skor Mentah \\
\hline 1 & $\mathrm{~A}$ & 100 & 65 \\
\hline 2 & $\mathrm{~B}$ & 100 & 66 \\
\hline 3 & $\mathrm{C}$ & 100 & 64 \\
\hline 4 & $\mathrm{D}$ & 100 & 65 \\
\hline 5 & $\mathrm{E}$ & 100 & 66 \\
\hline 6 & $\mathrm{~F}$ & 100 & 65 \\
\hline 7 & $\mathrm{G}$ & 100 & 65 \\
\hline 8 & $\mathrm{H}$ & 100 & 66 \\
\hline 9 & I & 100 & 68 \\
\hline 10 & $\mathrm{~J}$ & 100 & 68 \\
\hline 11 & $\mathrm{~K}$ & 100 & 64 \\
\hline 12 & $\mathrm{~L}$ & 100 & 65 \\
\hline 13 & $\mathrm{M}$ & 100 & 66 \\
\hline 14 & $\mathrm{~N}$ & 100 & 65 \\
\hline 15 & $\mathrm{O}$ & 100 & 66 \\
\hline 16 & $\mathrm{P}$ & 100 & 65 \\
\hline 17 & $\mathrm{Q}$ & 100 & 65 \\
\hline 18 & $\mathrm{R}$ & 100 & 66 \\
\hline 19 & $\mathrm{~S}$ & 100 & 65 \\
\hline 20 & $\mathrm{~T}$ & 100 & 65 \\
\hline 21 & $\mathrm{U}$ & 100 & 66 \\
\hline 22 & $\mathrm{~V}$ & 100 & 66 \\
\hline 23 & $\mathrm{~W}$ & 100 & 65 \\
\hline 24 & $\mathrm{X}$ & 100 & 69 \\
\hline 25 & $\mathrm{Y}$ & 100 & 65 \\
\hline 26 & $\mathrm{Z}$ & 100 & 65 \\
\hline 27 & AA & 100 & 65 \\
\hline 28 & $\mathrm{AB}$ & 100 & 64 \\
\hline
\end{tabular}




\begin{tabular}{|c|c|c|c|}
\hline 29 & $\mathrm{AC}$ & 100 & 68 \\
\hline 30 & $\mathrm{AD}$ & 100 & 66 \\
\hline 31 & $\mathrm{AE}$ & 100 & 65 \\
\hline 32 & $\mathrm{AF}$ & 100 & 66 \\
\hline 33 & $\mathrm{AG}$ & 100 & 68 \\
\hline 34 & $\mathrm{AH}$ & 100 & 65 \\
\hline 35 & $\mathrm{AI}$ & 100 & 69 \\
\hline 36 & $\mathrm{AJ}$ & 100 & 65 \\
\hline 37 & $\mathrm{AK}$ & 100 & 68 \\
\hline 38 & $\mathrm{AL}$ & 100 & 65 \\
\hline 39 & AM & 100 & 66 \\
\hline 40 & AN & 100 & 64 \\
\hline 41 & $\mathrm{AO}$ & 100 & 64 \\
\hline 42 & AP & 100 & 64 \\
\hline 43 & AQ & 100 & 65 \\
\hline 44 & AR & 100 & 65 \\
\hline 45 & AS & 100 & 68 \\
\hline 46 & AT & 100 & 65 \\
\hline 47 & $\mathrm{AU}$ & 100 & 65 \\
\hline 48 & AV & 100 & 66 \\
\hline 49 & AW & 100 & 66 \\
\hline 50 & AX & 100 & 64 \\
\hline 51 & AY & 100 & 64 \\
\hline 52 & AZ & 100 & 68 \\
\hline 53 & AAA & 100 & 64 \\
\hline 54 & AAB & 100 & 66 \\
\hline 55 & AAC & 100 & 64 \\
\hline 56 & AAD & 100 & 64 \\
\hline 57 & AAE & 100 & 64 \\
\hline 58 & AAF & 100 & 64 \\
\hline 59 & AAG & 100 & 64 \\
\hline 60 & AAH & 100 & 66 \\
\hline \multicolumn{2}{|c|}{ JUMLAH } & & 3929 \\
\hline
\end{tabular}

Berdasarkan data di atas skor tertinggi adalah 69 dan skor terendah adalah 64 dengan rata-rata nilai 65,48 .

\section{Nilai Post-Tes Kemampuan Menulis Puisi} Siswa Kelas VIII MTs Binaul Iman

Karang Sari (Y)

\begin{tabular}{|c|c|c|c|}
\hline No & Inisial & Skor Ideal & Skor Mentah \\
\hline 1 & A & 100 & 84 \\
\hline 2 & $\mathrm{~B}$ & 100 & 90 \\
\hline 3 & $\mathrm{C}$ & 100 & 86 \\
\hline 4 & $\mathrm{D}$ & 100 & 84 \\
\hline 5 & $E$ & 100 & 92 \\
\hline 6 & $\mathrm{~F}$ & 100 & 90 \\
\hline 7 & $\mathrm{G}$ & 100 & 86 \\
\hline 8 & $\mathrm{H}$ & 100 & 86 \\
\hline 9 & $\mathrm{I}$ & 100 & 92 \\
\hline 10 & $\mathrm{~J}$ & 100 & 90 \\
\hline 11 & $\mathrm{~K}$ & 100 & 84 \\
\hline 12 & $\mathrm{~L}$ & 100 & 84 \\
\hline 13 & $\mathrm{M}$ & 100 & 92 \\
\hline 14 & $\mathrm{~N}$ & 100 & 84 \\
\hline
\end{tabular}

\begin{tabular}{clll}
\hline 15 & $\mathrm{O}$ & 100 & 90 \\
\hline 16 & $\mathrm{P}$ & 100 & 84 \\
\hline 17 & $\mathrm{Q}$ & 100 & 84 \\
\hline 18 & $\mathrm{R}$ & 100 & 86 \\
\hline 19 & $\mathrm{~S}$ & 100 & 86 \\
\hline 20 & $\mathrm{~T}$ & 100 & 84 \\
\hline 21 & $\mathrm{U}$ & 100 & 90 \\
\hline 22 & $\mathrm{~V}$ & 100 & 86 \\
\hline 23 & $\mathrm{~W}$ & 100 & 86 \\
\hline 24 & $\mathrm{X}$ & 100 & 92 \\
\hline 25 & $\mathrm{Y}$ & 100 & 84 \\
\hline 26 & $\mathrm{Z}$ & 100 & 84 \\
\hline 27 & AA & 100 & 86 \\
\hline 28 & AB & 100 & 86 \\
\hline 29 & AC & 100 & 92 \\
\hline 30 & AD & 100 & 86 \\
\hline 31 & AE & 100 & 86 \\
\hline 32 & AF & 100 & 86 \\
\hline 33 & AG & 100 & 86 \\
\hline 34 & AH & 100 & 86 \\
\hline 35 & AI & 100 & 92 \\
\hline 36 & AJ & 100 & 84 \\
\hline 37 & AK & 100 & 92 \\
\hline 38 & AL & 100 & 84 \\
\hline 39 & AM & 100 & 86 \\
\hline 40 & AN & 100 & 84 \\
\hline 41 & AO & 100 & 86 \\
\hline 42 & AP & 100 & 84 \\
\hline 43 & AQ & 100 & 84 \\
\hline 44 & AR & 100 & 92 \\
\hline 45 & AS & 100 & 92 \\
\hline 46 & AT & 100 & 84 \\
\hline 47 & AU & 100 & 86 \\
\hline 48 & AV & 100 & 86 \\
\hline 49 & AW & 100 & 84 \\
\hline 50 & AX & 100 & 90 \\
\hline 51 & AY & 100 & 86 \\
\hline 52 & AZ & 100 & 86 \\
\hline 53 & AAA & 100 & 90 \\
\hline 54 & AAB & 100 & 92 \\
\hline 55 & AAC & 100 & 90 \\
\hline 56 & AAD & 100 & 84 \\
\hline 57 & AAE & 100 & 84 \\
\hline 58 & AAF & 100 & 84 \\
\hline 59 & AAG & 100 & 90 \\
\hline 60 & AAH & 100 & 90 \\
\hline & & & 5275 \\
\hline & & & \\
\hline & JUMLAH & & \\
\hline
\end{tabular}

Berdasarkan tabel di atas maka di peroleh skor tertinggi adalah 92 dan skor terendah adalah 60 dengan rata-rata nilai 87,91 .

Hasil penelitian pre test dan post test yang di dapat dari hasil penelitian selanjutnya penulis akan menganalis korelari hasil pre test dan post test 


\section{Korelasi Variabel X dan Variabel Y Siswa}

\section{Kelas VIII MTs Binaul Iman Karang Sari}

\begin{tabular}{|c|c|c|c|c|c|c|}
\hline No & Inisial & $\mathbf{X}$ & $\mathbf{Y}$ & $\mathrm{X}^{2}$ & $\mathrm{Y}^{2}$ & XY \\
\hline 1 & $\mathrm{~A}$ & 65 & 84 & 4225 & 7056 & 5460 \\
\hline 2 & B & 66 & 90 & 4356 & 8100 & 5940 \\
\hline 3 & $\mathrm{C}$ & 64 & 86 & 4096 & 7396 & 5504 \\
\hline 4 & $\mathrm{D}$ & 65 & 84 & 4225 & 7056 & 5460 \\
\hline 5 & $E$ & 66 & 92 & 4489 & 8649 & 6231 \\
\hline 6 & $\mathrm{~F}$ & 65 & 90 & 4225 & 8100 & 5850 \\
\hline 7 & $\mathrm{G}$ & 65 & 86 & 4225 & 7744 & 5720 \\
\hline 8 & $\mathrm{H}$ & 66 & 86 & 4356 & 7744 & 5808 \\
\hline 9 & I & 68 & 92 & 4489 & 8649 & 6231 \\
\hline 10 & $\mathrm{~J}$ & 68 & 90 & 4489 & 8100 & 6030 \\
\hline 11 & $\mathrm{~K}$ & 64 & 84 & 4096 & 7056 & 5376 \\
\hline 12 & $\mathrm{~L}$ & 65 & 84 & 4225 & 7056 & 5460 \\
\hline 13 & $\mathrm{M}$ & 66 & 92 & 4489 & 8649 & 6231 \\
\hline 14 & $\mathrm{~N}$ & 65 & 84 & 4225 & 7056 & 5460 \\
\hline 15 & $\mathrm{O}$ & 66 & 90 & 4356 & 8100 & 5940 \\
\hline 16 & $\mathrm{P}$ & 65 & 84 & 4225 & 7056 & 5460 \\
\hline 17 & Q & 65 & 84 & 4225 & 7056 & 5460 \\
\hline 18 & $\mathrm{R}$ & 66 & 86 & 4356 & 7744 & 5808 \\
\hline 19 & $\mathrm{~S}$ & 65 & 86 & 4225 & 7744 & 5720 \\
\hline 20 & $\mathrm{~T}$ & 65 & 84 & 4225 & 7056 & 5460 \\
\hline 21 & $\mathrm{U}$ & 66 & 90 & 4356 & 8100 & 5940 \\
\hline 22 & $\mathrm{~V}$ & 66 & 86 & 4356 & 7744 & 5808 \\
\hline 23 & $\mathrm{~W}$ & 65 & 86 & 4225 & 7744 & 5720 \\
\hline 24 & $X$ & 69 & 92 & 4761 & 8649 & 5417 \\
\hline 25 & $\mathrm{Y}$ & 65 & 84 & 4225 & 7056 & 5460 \\
\hline 26 & $\mathrm{Z}$ & 65 & 84 & 4225 & 7056 & 5460 \\
\hline 27 & $\mathrm{AA}$ & 65 & 86 & 4225 & 7396 & 5590 \\
\hline 28 & $\mathrm{AB}$ & 64 & 86 & 4096 & 7396 & 5504 \\
\hline 29 & $\mathrm{AC}$ & 68 & 92 & 4624 & 8464 & 6256 \\
\hline 30 & $\mathrm{AD}$ & 66 & 86 & 4356 & 7396 & 5676 \\
\hline 31 & $\mathrm{AE}$ & 65 & 86 & 4225 & 7396 & 5590 \\
\hline 32 & $\mathrm{AF}$ & 66 & 86 & 4356 & 7396 & 5676 \\
\hline 33 & $\mathrm{AG}$ & 68 & 86 & 4624 & 7396 & 5848 \\
\hline 34 & $\mathrm{AH}$ & 65 & 86 & 4225 & 7396 & 5590 \\
\hline 35 & $\mathrm{AI}$ & 69 & 92 & 4624 & 8464 & 6348 \\
\hline 36 & $\mathrm{AJ}$ & 65 & 84 & 4225 & 7056 & 5460 \\
\hline 37 & $\mathrm{AK}$ & 68 & 92 & 4489 & 8464 & 6164 \\
\hline 38 & $\mathrm{AL}$ & 65 & 84 & 4225 & 7056 & 5460 \\
\hline 39 & $\mathrm{AM}$ & 66 & 86 & 4356 & 7396 & 5676 \\
\hline 40 & AN & 64 & 84 & 4096 & 7056 & 5376 \\
\hline 41 & $\mathrm{AO}$ & 64 & 86 & 4096 & 7396 & 5504 \\
\hline 42 & $\mathrm{AP}$ & 64 & 84 & 4096 & 7056 & 5376 \\
\hline 43 & $\mathrm{AQ}$ & 65 & 84 & 4225 & 7056 & 5460 \\
\hline 44 & $\mathrm{AR}$ & 65 & 92 & 4225 & 8464 & 5980 \\
\hline 45 & $\mathrm{AS}$ & 68 & 92 & 4624 & 8464 & 6256 \\
\hline 46 & AT & 65 & 84 & 4225 & 7056 & 5460 \\
\hline 47 & $\mathrm{AU}$ & 65 & 86 & 4225 & 7396 & 5590 \\
\hline 48 & $\mathrm{AV}$ & 66 & 86 & 4356 & 7744 & 5808 \\
\hline 49 & AW & 66 & 84 & 4356 & 7056 & 5376 \\
\hline 50 & $\mathrm{AX}$ & 64 & 90 & 4096 & 8100 & 5940 \\
\hline 51 & $\mathrm{AY}$ & 64 & 86 & 4225 & 7744 & 5720 \\
\hline 52 & $\mathrm{AZ}$ & 68 & 86 & 4624 & 7744 & 5984 \\
\hline 53 & AAA & 64 & 90 & 4096 & 8100 & 5760 \\
\hline 54 & $\mathrm{AAB}$ & 66 & 92 & 4356 & 8649 & 5952 \\
\hline 55 & AAC & 64 & 90 & 4096 & 8100 & 5940 \\
\hline 56 & AAD & 64 & 84 & 4096 & 7056 & 5376 \\
\hline 57 & AAE & 64 & 84 & 4096 & 7056 & 5376 \\
\hline
\end{tabular}

\begin{tabular}{lllllll}
\hline 58 & AAF & 64 & 84 & 4096 & 7056 & 5376 \\
\hline 59 & AAG & 64 & 90 & 4096 & 8100 & 5760 \\
\hline 60 & AAH & 66 & 90 & 4356 & 8100 & 5940 \\
\hline jumlah & 3929 & 5275 & 257379 & 464395 & 345572 \\
\hline
\end{tabular}

Berdasarkan tabel analisis tersebut,

maka diketahui:

$\mathrm{N}=60$

$\Sigma X=3929$

$\Sigma \mathrm{Y}=5275$

$\Sigma \mathrm{X}^{2}=257379$

$\Sigma Y^{2}=464395$

$\Sigma X Y=345572$

$r_{x y}=\frac{n\left(\sum x y\right)-\left(\sum x\right) \cdot \sum y}{\sqrt{\left\{n \cdot \sum x^{2}-\left(\sum x\right)^{2}\right\} \cdot\left\{n \cdot \sum y^{2}-\left(\sum y\right)^{2}\right\}}}$

$r_{x y}=\frac{60(345572)-(3929 \times 5275)}{\sqrt{\left\{60 \times 257379-(3929)^{2}\right\} .\left\{60 \times 464395-(5275)^{2}\right\}}}$

$r_{x y}=\frac{20734320-20725475}{\sqrt{\{15442740-15437041\} \cdot\{27863700-27825625\}}}$

$r_{x y}=\frac{8845}{\sqrt{\{5699\} .\{38075\}}}$

$r_{x y}=\frac{8845}{\sqrt{216989425}}$

$r_{x y}=\frac{8845}{14730,56}$

$r_{x y}=0,60$

Berdasarkan hasil analisis korelasi koofisien "r" sebesar 0,6 yang berarti memiliki korelasi sedang.

Pengujian signifikan koefisien korelasi dapat di uji dengan tes " $t$ " yaitu dengan rumus sebagai berikut:

$\mathrm{t}=\frac{r \sqrt{n-2}}{\sqrt{1-r^{2}}}$

keterangan $: \mathrm{t}=$ Nilai hitung

$$
\begin{gathered}
\mathrm{r}=\text { Nilai korelasi } \\
\mathrm{N}=\text { Jumlah sampel }
\end{gathered}
$$


Signifikan koefisien korelasi nilai hitung, yaitu

Diketahui: $\quad r=0,60$

$$
\mathrm{N}=60
$$

$t=\frac{0,60 \sqrt{60-2}}{\sqrt{1-0,60^{2}}}$

$t=\frac{0,60 \sqrt{58}}{\sqrt{1-0,36}}$

$$
t=\frac{0,60 \sqrt{58}}{\sqrt{0,64}}
$$

$t=\frac{0,60 \times 7,61}{0,8}$

$t=5,70$

Untuk mengetahui metode kooperatif tipe example non example terhadap kemampuan menulis puisi, terlebih dahulu harus menentukan Determinasi yaitu mengkuadratkan koefisien korelasi sebagai berikut :

$\mathrm{D}=\mathrm{r}^{2}$

$\mathrm{D}=0,60^{2}$

$\mathrm{D}=0,36$

Jadi dinyatakan dalam presentase, maka besarnya adalah

$\mathrm{D}=0,36 \times 100 \%$

$\mathrm{D}=36 \%$

Melalui perhitungan diperoleh koefisien determinasi sebesar $36 \%$ berarti metode kooperatif tipe example non example mempengaruhi kemampuan menulis puisi.

\section{PEMBAHASAN PENELITIAN}

Uji signifikan dilakukan dengan kriteria sebagai berikut :

Ha ditolak dan Ho diterima jika thitung $<$ tabel

Ha diterima dan Ho ditolak jika thitung $>$ ttabel

Berdasarkan dari data yang sudah diperoleh, selanjutnya harus menentukan pengujian di bawah ini, yaitu :

1. Menentukan dk (derajat kebebasan)

$$
\begin{aligned}
\mathrm{Dk} & =\mathrm{N}-2 \\
& =60-2 \\
& =58
\end{aligned}
$$

2. Uji 2 pihak

jika thitung $\geq$ tabel maka signifikan

jika thitung $\leq$ tabel maka tidak signifikan

untuk penelitian kependidikan taraf signifikan (keberanian) yang dipakai a $=0,05 \mathrm{dan} \mathrm{dk}=58$

diketahui: tabel $=2,021$

$$
\text { thitung }=5,70
$$

maka thitung $\geq$ tabel yaitu $5,70 \geq$

2,021

Hasil perhitu Pre-Test (X) dan Post Test (Y) Siswa Kelas VIII MTs Binaul Iman Karang Sari

\begin{tabular}{cccccc}
\hline $\begin{array}{c}\text { Jumlah } \\
\text { Siswa }\end{array}$ & X & Y & XY & r & T \\
\hline 60 & 3929 & 5275 & 345572 & 0,60 & 2,021 \\
\hline
\end{tabular}

Berdasarkan analisis data yang dilakukan oleh peneliti, maka diperoleh skor rata-rata tes menulis puisi kelas VIII MTs Binaul Iman Karang Sari adalah 65,48 dengan skor tertinggi 69 dan skor terendah 64. Skor 
rata-rat menulis puisi dengan menggunakan metode kooperatif tipe example non example siswa kela VIII Mts Binaul Iman Karang Sari adalah 87,91 dengan skor tertinggi 93 dan skor terendah 84. Dengan demikian pembelajaran dengan menggunakan metode kooperatif tipe example non example dinyatakan baik dengan hasil korelasi sebesar rxy $=0,60$.

Berdasarkan data di atas maka dapat dinyatakan bahwa Ha diterima keberadaannya dan Ho ditolak (thitung > ttabel). Jadi, ada pengaruh yang signifikan dari penelitian tentang pengaruh metode kooperatif tipe example non example terhadap kemampuan menulis opuisi oleh siswa kelas VIII MTs Binaul Iman Karang Sari.

\section{SIMPULAN}

Berdasarkan hasil pembahasan pada penelitian ini dapat disimpulkan bahwa:

1. Telah dilakukan pre-test dan post-tes pada kemampuan menulis puisi oleh siswa kelas VIII dan hasilnya mengalami peningkatan. Hal ini dapat dilihat dari nilai rata-rata yang diperoleh siswa saat dilakukan pre-test adalah 65,48 sedangkan rata-rata nilai yang diperoleh siswa setelah dilakukan post-tes mengenai kemampuan menulis puisi adalah 87,91 .
2. Besar koofisien korelasi adalah 0,60 dengan peringkat korelasi sedang. Dan diperoleh $\mathrm{t}$ hitung sebesar $5,70, \mathrm{t}$ tabel sebesar 2,021 berarti thitung $\geq$ tabel yaitu $5,70 \geq 2,02$. Maka dapat disimpulkan bahwa jika thitung $\geq$ tabel maka hal ini berarti ada pengaruh model kooperatif tipe example non example terhadap kemampuan menulis puisi siswa kelas VIII MTs Binaul Iman Karang Sari.

\section{DAFTAR PUSTAKA}

Arikunto, Suharsimi. 2016. Pr0sedur Penelitian, suatu pendekatan Praktik. Jakarta : PT Rineka Cipta.

Huda, Miftahul. 2014 Model-Model Pengajaran dan Pembelajaran. Yogyakarta : Pustaka Pelajar.

Ngalimun. 2014. Strategi dan Model Pembelajaran. Banjarmasin : Aswaja Pressindo.

Rusman. 2014. Model-Model Pembelajaran (Mengembangkan Profesionalisme Guru). Jakarta : Raja Grafindo Pesada.

Semi, M. Atar. 2010. Menulis Efektif. Padang : Angkasa Raya.

Shoimin, Aris. 2016. 68 Model Pembelajaran Inovatif dalam Kurikulum 2013. Yogyakarta : Ar-Ruzz Media.

Siwanto, Wahyudi. 2012. Pengantar Teori Sastra. Jakarta : PT Grasindo

Sukardi. 2013. Metodologi Penelian Pendidikan.Jakarta : PT Bumi Aksara. 
Tarigan, Hendry Guntur. 2017. Prinsip-Prinsip

Dasar Sastra. Bandung : Angkasa.

Waluyo, Herman. 2005. Apresiasi Puisi.

Jakarta : PT Gramedia Pustaka Utama. 